\title{
Keratoacanthoma or squamous cell carcinoma
}

\section{Kaoutar Laamari, Sara Oukarfi, Sara Elloudi, Zakia Douhi, Hanane Baybay, Fatima Zahra Mernissi, Lotfi Aouinti, Ayoub Charai, Dounia Kamal, Mohamed Nourdine El Amine El Alami}

\author{
${ }^{1}$ Departement of Dermatology, University Hospital Hassan II, Fes, Morocco, ${ }^{2}$ Departement of Otorhinolaryngology, \\ University Hospital Hassan II, Fes, Morocco
}

Corresponding author: Dr. Kaoutar Laamari, E-mail: Kaoutar.laamari1@gmail.com

\begin{abstract}
Keratoacanthoma (KA) is classically a benign skin neoplasm that occurs on damaged photo. But the relationship between squam cell carcinome and keratoacanthoma is still on. To date, no clinical or histological criteria can confirm the diagnosis. The very different biologic tendency of rapid onset and spontaneous regression seen in typical KAs has led many clinicians and dermatopathologists to view this lesion as a noninvasive benign entity distinct from SCC. Many authors suggest that there is no single histopathological diagnostic criterion to differentiate KA from traditional SCC. We report A cases of a patients with a Keratoacanthoma that behaved as an invasive SCC.
\end{abstract}

Key words: Keratoacanthoma; Squamous cell; Carcinoma

\section{INTRODUCTION}

Keratoacanthoma (KA) is a skin cancer that occurs on damaged photo skin affecting the hair follicle consisting of proliferative, mature and involutional stage. The close relationship between squamous cell carcinoma and keratoacanthoma has always been debated. Some look to the benign origin, other than keratoacanthoma is a sub-type of carcinoma and other that it is a precursor [1] but so far the difference between the two is still relevant.

We report A cases of a patients with a Keratoacanthoma that behaved as an invasive SCC.

\section{CASE REPORTS}

\section{Case 1}

Male patient aged 62, which has a burgeoning lesion at the temporal level evolving for 4 years, non-painful and non-pruriginous. The dermatological examination showed the presence of a well-defined, coarsely rounded, ulcerous budding tumor, about $3 \mathrm{~cm}$ long, with a central crater surmounted by acidic crusts (Fig. 1). Dermoscopy showed the ulceration, scabs and some peripheral linear vascularization (Fig. 2). The suspicious diagnoses were squamous cell carcinoma and keratoacanthoma. A cutaneous biopsy was performed and we could see the presence of an epithelial proliferation, of squamous nature of exophytic and endophytic growth with a central crater filled with mature keratin without cytonuclear atypies in favor of a keratoacanthoma. An excisional biopsy was completed, the histology showed an epithelial proliferation, of squamous nature of exophytic and endophytic growth with a central crater filled with mature keratin, with an irregular deep limit made of infiltrating carcinomatous cells revealing a squamous cell carcinoma. A new excision was performed with healthy margins.

\section{DISCUSSION}

Keratoacanthoma (KA) is classically regarded as a benign skin neoplasm, Originally described in 1889 by Hutchinson [2] as a "crater Facial ulcer", these lesions often affect elderly people of both sexes with Fitzpatrick's disease with sun-damaged skin and / or

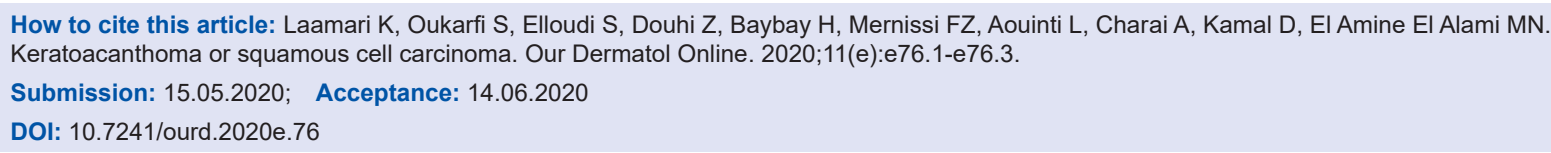




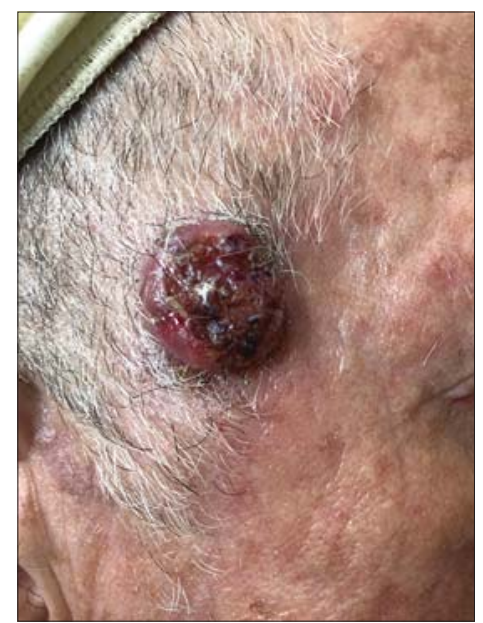

Figure 1: The presence of a well-defined, coarsely rounded, ulcerous budding tumor, about $3 \mathrm{~cm}$ long, with a central crater surmounted by acidic crusts.

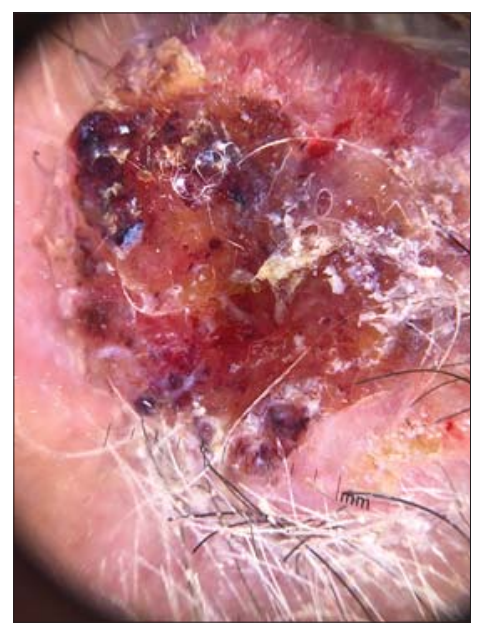

Figure 2: Ulceration, scabs and some peripheral linear vascularization.

history of trauma. The usual variant of KA appears in the form pink to pink fleshy nodule with a central keratinous plug that develops rapidly, in 1-2 months, and then undergoes a spontaneous regression over a period of 3 to 6 months, generally leaving no cosmetic effect. The sites most frequently affected are the face and extremities, but it can occur anywhere on the body. When multiple lesions are present, the possibility of syndromic conditions should be considered [3].

Histologically, KA exhibits an endo-exophytic, symmetrical and crateriform epidermoid proliferation feature composed of pale and vitreous keratinocytes and may exhibit neutrophilic and micro-abscess cells loaded with eosinophils. This lesions are often only superficially invasive. It is important to note that the microscopic aspect will vary depending on the stage at which the lesion is biopsied. Nevertheless, their clinical behavior seems to be benign [4].

An important issue regarding $\mathrm{KA}$ is its relationship to squamous cell carcinoma (SCC). SCC arising on sun-damaged skin is typically a slowgrowing, persistent, locally invasive malignancy that does rarely metastasize $[5,6]$.

The very different biologic tendency of rapid onset and spontaneous regression seen in typical KAs has led many clinicians and dermatopathologists to view this lesion as a noninvasive benign entity distinct from SCC. Many authors suggest that there is no single histopathological diagnostic criterion to differentiate KA from traditional SCC.

The term "KA-like SCC" may be used and it was roughly defined by Schwartz et al.as lesions having a histopathological resemblance to KA but with an eccentric architecture and prominent atypical cytological features [7].

Thus a skin biopsy never allows to distinguish between the two entities. It would be most imprudent to claim on a fragment that such a lesion is benign [8]. The more often, a partial biopsy shows an epidermoid proliferative lesion, never allowing to discuss a benign lesion. Practically, biopsies should be discouraged and opt for complete excision of these tumors [9].

\section{CONCLUSION}

The differentiation between a keratoacanthoma and a squamous cell carcinoma is still debated. To date, no clinical or histological criteria can confirm the diagnosis.

Nevertheless, it is advisable to perform a complete excision of the KA-type CSC, the biopsy being of no use to try to distinguish it from the classical CSC.

\section{Consent}

The examination of the patient was conducted according to the Declaration of Helsinki principles.

The authors certify that they have obtained all appropriate patient consent forms. In the form the patient(s) has/have given his/her/ their consent for his/her/their images and other clinical information to be reported in the journal. The patients understand that their names and initials will not be published and due efforts will be made to conceal their identity, but anonymity cannot be guaranteed. 


\section{REFERENCES}

1. Al-Kamel MA. Keratoacanthoma of the nose coexisted with xeroderma pigmentosum in a Yemeni child: A rare case. Our Dermatol Online. 2016;7:419-21.

2. Hutchinson J. Morbid growths and tumours: 1: the "crateriform ulcer of the face", a form of acute epithelial cancer. Trans Pathol Soc London 1889.

3. Bartoš V, Kullová M. Cutaneous squamous cell carcinoma in situ with extensive clear cell change - A report of two cases. Our Dermatol Online. 2017;8:311-4.

4. Bhat YJ. Keratoacanthoma - Non surgical treatment modalities. Our Dermatol Online. 2017;8:358-9.

5. Kwiek B, Schwartz RA. Keratoacanthoma (KA): An update and review. J Am Acad Dermatol. 2016;74:1220-33.

6. Nagarajan P. Differentiating keratoacanthoma from squamous cell carcinoma-In quest of the holy grail. J Cutan Pathol. 2020;47:418-20

7. Mohamed M, Anderson Sohkhlet KD, Samayam A. Tattoo reaction: Case series. Our Dermatol Online. 2018;9:200-2.

8. Kim Y, Helm KF, Billingsley EM, Lam C. Spontaneous regression of a keratoacanthoma centrifugum marginatum. Dermatol Pract Concept. 2019;9:157-9.

9. Gupta M. Squamous cell carcinoma arising over seborrhoeic keratosis - A rare presentation. Our Dermatol Online. 2018;9:71-2.

Copyright by Kaoutar Laamari, et al. This is an open access article distributed under the terms of the Creative Commons Attribution License, which permits unrestricted use, distribution, and reproduction in any medium, provided the original author and source are credited.

Source of Support: Nil, Conflict of Interest: None declared. 